\title{
Optimized dimensioning of steel-concrete composite beams
}

\section{Dimensionamento otimizado de vigas mistas de aço e concreto}

\author{
A. R. SILVA \\ amilton@ufop.edu.br \\ https://orcid.org/0000-0002-7122-252X \\ T. A. RODRIGUES a \\ tati10rodr@gmail.com \\ https://orcid.org/0000-0002-2488-4942
}

\begin{abstract}
The steel-concrete composite sections are often used in civil building in Brazil and around the world. The connection of the steel profile and the concrete slab increases the performance of the composite structural element due to the use of the advantages of each material. In this article, a bar element is used with an interface element for nonlinear analysis of steel-concrete composite beams with partial interaction. The objective is to develop an algorithm that uses this analysis tool to design steel-concrete composite beams looking for project optimized in terms of material costs. Defined spans, supports, ultimate and service load, an optimization algorithm is used to define the dimensions of the rectangular cross section of the concrete slab, I-shaped steel profile, and the reinforcement bars of the concrete slab, so that the quantity of these materials are the minimum to ensure structural safety, considering the ultimate and service limit states. The design constraints are obtained from building code requirements for concrete, steel and composite structures. The objective function is defined as the cost per unit length of the composite beam, obtained from the unit cost of each material, steel, concrete and reinforcement. In the optimization process, the iterative method sequential linear programming is used, in which the nonlinear problem is approximated by a sequence of linear problems, which has its optimum point defined step by step by the Simplex method. Examples of composite beams with ultimate loads defined in the literature were used to validate the implementations. Other examples were analyzed, being evaluated at each iteration the restrictions and objective function to verify the efficiency of the algorithm.
\end{abstract}

Keywords: piles, PIT, reinforcement effects.

\section{Resumo}

As seções mistas de aço e concreto estão cada vez mais sendo utilizadas na construção civil, tanto no cenário mundial quanto no Brasil. O trabalho conjunto do perfil de aço e da laje de concreto aumenta consideravelmente o desempenho do elemento estrutural misto devido ao aproveitamento das vantagens de cada material. Neste trabalho, é utilizado um elemento de barra em conjunto com um elemento de interface para análise não linear de vigas mistas de aço e concreto com interação parcial. O objetivo é montar um algoritmo que utilize essa ferramenta de análise para dimensionar vigas mistas de aço e concreto buscando um projeto otimizado em termos de gastos dos materiais. Definidos os vãos, os apoios, os carregamentos para verificação última e de serviço, um algoritmo de otimização é utilizado para definir as dimensões da seção transversal retangular da laje de concreto, do perfil I de aço e das barras de reforço da laje de concreto, de forma que a quantidade desses materiais seja mínima, garantindo a segurança estrutural, considerando os estados limites último e de serviço. As restrições de projeto são aquelas definidas em normas referentes ao dimensionamento de elementos lineares de concreto, aço ou misto. A função objetivo é definida como sendo o custo por metro linear da viga mista, obtida a partir do custo de cada material, aço, concreto e armadura. No processo de otimização é utilizado o método iterativo de programação linear sequencial, no qual o problema não linear é aproximado por uma sequência de problemas lineares, que tem seu ponto ótimo definido a cada passo usando o método Simplex. Exemplos de vigas mistas para as quais foram definidas suas cargas últimas foram utilizados para validação das implementações. Outros exemplos foram analisados para os quais foram controlados a cada iteração as restrições e função objetivo verificando a funcionalidade do algoritmo.

Palavras-chave: otimização, vigas mistas, método simplex, programação linear sequencial.

Universidade Federal de Ouro Preto, Escola de Minas, Departamento de Engenharia Civil, Programa de Pós Graduação em Engenharia Civil, Ouro Preto, MG, Brasil. 


\section{Introdution}

With the increasing use of computers together with computational mechanics to solve structural analysis problems, optimization processes have become an important tool for engineering. The optimization techniques aim to extract the maximum performance from the product or service. In structural engineering they can be applied in order to find, among the many possible solutions, the one that is more economical and meets the architectural, safety and constructive conditions.

Steel-concrete composite beams are structural elements composed of a rolled, cold-formed or built-up steel member attached to a conventional or steel-deck concrete slab by means of shear connectors. In most of the composite beam designs there are a greater number of variables than the number of equations related to these variables. Thus, it is necessary to assign values to some variables in order to calculate the others. That is, there exists an unlimited number (continuous variables) or large (discrete variables) of solutions to the problem. In view of this context, the objective of this work is to create an algorithm that uses tools for composite beam structural analysis searching for an optimized design in terms of quantity and cost of materials. In other words, defined spans, supports and loads for service and ultimate analyis of a composite beam, an optimization algorithm is used to define l-shaped steel section dimensions, rectangular concrete slab section dimensions, and the quantity and diameter of the reinforcement bars so that the amount of these materials is the minimum required to meet the safety criterion considering the ultimate and service limit state. In the verification of the ultimate and service limit state a structural analysis of the composite beam with partial interaction is required. For this, the finite element method is used simulating the composite beam by means of bar and interface elements developed by Silva and Sousa [1]. In this numerical simulation the bar elements simulate the concrete slab and the steel beam, while the interface element connects the bar elements and simulates the deformable connection at the interface between the concrete slab and the steel beam. Several works can be found in the literature for nonlinear numerical analysis of steel-concrete composite beams with partial interaction using bar finite elements [2-11].

Several works on optimization can be found in the literature in the most diverse areas of knowledge. Kravanja et al. [12] optimized composite beams in which the reinforced concrete slab is connected to a built-up steel section of type I. The technique used was MINLP (Mixed Integer Nonlinear Programming) that solves problems of nonlinear optimization with discrete and continuous variables. For this analysis, the authors verified the ultimate and service limit state and the objective function considers execution and material cost.

Kravanja et al. [13] investigated composite beams formed by a concrete slab connected to a doubly symmetrical built-up steel section of type I and composite beams formed by the association of a concrete slab with a steel truss beam. The study was performed applying structural optimization through nonlinear programming. Also using nonlinear programming using the reduced gradient technique, Klanšek and Kravanja developed some works in the area of composite floor optimization [14-17].

Senouci and Al-Ansari [18] developed a genetic algorithm model to optimize the cost of composite beams, including the cost of concrete, steel profile and shear connectors. For this, the model was formulated in two main stages: the first one is to determine most important variables in the composite beam design, and the second is to formulate the optimization of the total cost of the comosite beams. Abadi and Kaveh [19] studied the cost optimization of a composite floor system using a harmonic search algorithm. In the objective function, the authors considered only the costs of the materials (concrete, steel and connectors) and the project constraints are defined according to design code. Two examples of composite floors were evaluated to study the model developed and the authors concluded that the method was efficient in the search for the best solution of the structural optimization problem.

Silva et al. [20] presented the optimization of steel-concrete composite beams modeled and discretized in bar finite elements using the linear programming method associated with the Simplex method. The authors considered as design variables the cross-sectional dimensions and the stiffness of the deformable connection. The design constraints were defined from the maximum stresses in the materials obtained considering physical linear analysis.

\section{Finite Elements for composite beam nonlinear analysis}

In order to verify the design constraints related to the optimized design of steel-concrete composite beams, a composite beam structural analysis is required. For this, two finite elements, a bar element and an interface element [1], are used in this work.

\subsection{Bar Element}

Equations 1 and 2 define the axial and transverse displacements of any point in the bar element with reference axis coincident with the axis of the bar. These equations were defined considering the basic hypotheses of the Bernoulli-Euler beam theory.

$u(x, y)=u^{0}(x)-y^{\prime} v(x)$

$v(x, y)=v^{o}(x)$

In Equations 1 and 2 the superscript 0 indicates a reference axis adopted to represent the three-dimensional beam by a bar element. Applying the Green-Lagrange strain tensor to the displacement equations the equation for axial deformation in the bar element is obtained. Applying the virtual works principle we arrive at the internal force vector and tangent stiffness matrix given by Equations 3 and 4 for a bar element.

$\mathbf{f}_{\text {int }}=\int_{L}\left\{\begin{array}{c}N \boldsymbol{\Phi}_{u}{ }^{\prime} \\ -M \boldsymbol{\Phi}_{v}{ }^{\prime \prime}\end{array}\right\} d x$

$\mathbf{K}_{T}=\int_{L}\left[\begin{array}{c}\boldsymbol{\Phi}_{u}{ }^{\prime}\left(\frac{\partial N}{\partial \mathbf{q}}\right)^{T} \\ -\boldsymbol{\Phi}_{v}{ }^{\prime \prime}\left(\frac{\partial M}{\partial \mathbf{q}}\right)^{T}\end{array}\right] d x$

In Equations 3 and $4, N=\int_{A} \sigma_{x} d A$ and $M=\int_{A} \sigma_{x} y d A$ are normal force and bending moment in the cross section of beam. The terms of the vectors $\Phi_{u}$ and $\Phi_{v}$ are given by shape functions that approximate the axial and transverse displacements equations from the values of these displacements given at specific points of the bar element. In this paper the two-node bar element with three degrees of freedom per node is used; so vector $\Phi_{u}$ has two terms 
(linear interpolation of axial displacements) and vector $\Phi_{v}$ has 4 terms (cubic interpolation of transverse displacements). For the twonode bar element, $q=\left[\begin{array}{lllll}u_{1} & u_{2} & v_{1} & v_{1}^{\prime} & v_{2} v_{2}^{\prime}\end{array}\right]^{\top}$ is the nodal displacement vector.

\subsection{Interface element}

Considering composite beam simulated by a bar element for the section above of the slip interface and another bar element for the section below that interface, the interface element has the function of connecting these bar elements and simulating the deformable connection at the slip interface.

Figure 1 shows the deformation of a composite beam segment considering Bernoulli-Euler beam theory. In a rectangular interface element of zero thickness, the displacements considered are the relative movements between the upper and lower faces in the horizontal and vertical direction relative to the axis of the element. These displacements are presented in Equations 5 and 6 , where $w_{h}$ is the relative horizontal displacement and $\mathrm{w}_{\mathrm{v}}$ the relative vertical displacement.

$w_{h}(x)=u_{2}(x)-u_{1}(x)+\left(y_{2}-d\right) \theta_{2}(x)-\left(y_{1}-d\right) \theta_{1}(x)$

$w_{v}(x)=v_{2}(x)-v_{1}(x)$

Similar to the bar element is used the of virtual works principle for the development of the formulation of the zero thickness rectangular interface element. Since $S_{b}$ is the shear force per unit length related to the horizontal relative displacement and $N_{b}$ the normal force per unit length related to the vertical relative displacement, we arrive at the Equations 7 and 8 for internal force vector and the tangent stiffness matrix to the interface element.

$\mathbf{f}_{\text {int }}=\int_{L}\left\{\begin{array}{c}\left(d-y_{1}\right) S_{b} \boldsymbol{\Phi}_{v}^{\prime}-N_{b} \boldsymbol{\Phi}_{v} \\ S_{b} \boldsymbol{\Phi}_{u} \\ \left(y_{2}-d\right) S_{b} \boldsymbol{\Phi}_{v}^{\prime}+N_{b} \boldsymbol{\Phi}_{v}\end{array}\right\} d x$
$-\boldsymbol{\Phi}_{u}\left(\frac{\partial S_{b}}{\partial \mathbf{q}}\right)^{T}$
$\mathbf{K}_{T}=\int_{L}\left\{\begin{array}{c}\left(d-y_{1}\right) \boldsymbol{\Phi}^{\prime}{ }_{v}\left(\frac{\partial S_{b}}{\partial \mathbf{q}}\right)^{T}-\boldsymbol{\Phi}_{v}\left(\frac{\partial N_{b}}{\partial \mathbf{q}}\right)^{T} \\ \boldsymbol{\Phi}_{u}\left(\frac{\partial S_{b}}{\partial \mathbf{q}}\right)^{T} \\ \left(y_{2}-d\right) \boldsymbol{\Phi}_{v}^{\prime}\left(\frac{\partial S_{b}}{\partial \mathbf{q}}\right)^{T}+\boldsymbol{\Phi}_{v}\left(\frac{\partial N_{b}}{\partial \mathbf{q}}\right)^{T}\end{array}\right\} d x$
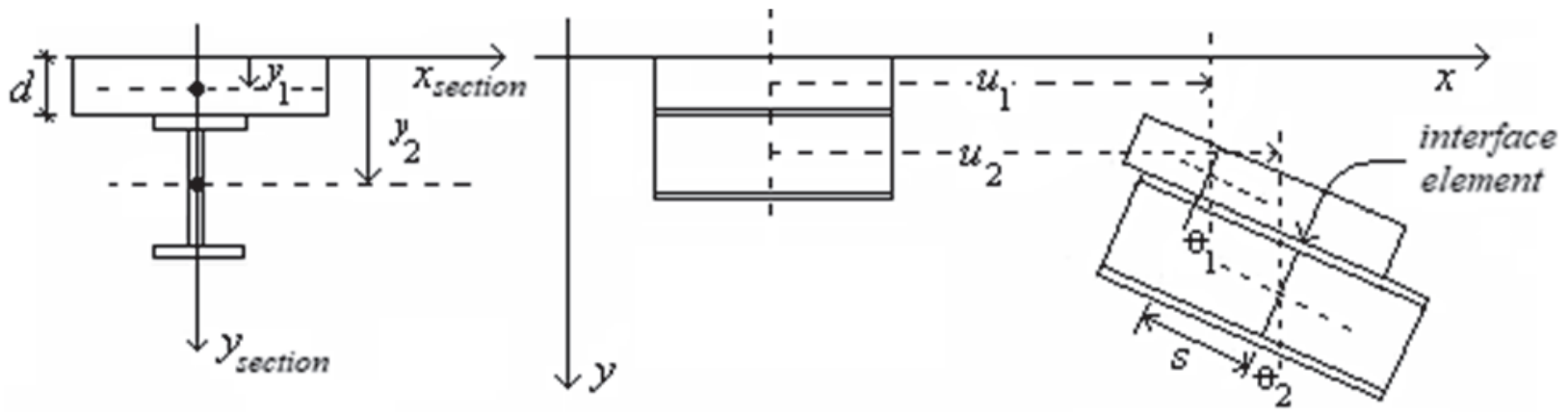

The interface element is a rectangular element of 4 nodes and The interface element is a rectangular element of 4 nodes and three degrees of freedom per node; thus $\mathrm{q}^{\top}=\left[\mathrm{q}_{1}^{\top} \mathrm{q}_{2}^{\top}\right]$, with $\mathrm{q}_{\alpha}(\alpha=1,2)$ being the nodal displacement vector of the bar element above and below of the interface. $\Phi_{u}$ and $\Phi_{v}$ are column vectors as presented in the previous item.

\section{Optimization}

This topic presents the considerations related to the studied problem, such as objective function, constraints and design variables. Also presented is the optimization method used in the analysis of nonlinear constrained optimization problem.

\subsection{Objective function}

For a same structural problem there are several feasible projects, some better than others in terms of some parameter of comparison, such as the amount of material used. Thus, an objective function is established to define a numerical criterion relating a given set of variables with the objective to obtain an optimized project.

In this article the objective is to determine the minimum cost of steel-concrete composite beams subjected to simple bending. Therefore, it is necessary to determine the minimum of the objective function given by Equation 9, where: $b$ is the concrete slab width, $h$ is the concrete slab height, $b_{f i}, b_{f s}$, and $b_{w}$ are lower and upper flanges width and web width, $t_{f i}, t_{f s}$ and $t_{w}$, lower and upper flange thickness and web thickness, $A_{s 1}$ and $A_{s 2}$ are lower and upper reinforcement areas of the concrete slabs, $C_{a}, C_{c}$ and $C_{b}$ are costs of profile steel, reinforcement bar steel, and concrete slab.

$f(\mathbf{x})=(b h) C_{c}+\left(b_{f i} t_{f i}+b_{f s} t_{f s}+b_{w} t_{w}\right) C_{a}+\left(A_{s 1}+A_{s 2}\right) C_{b}$

This function was defined for non-symmetric l-shaped in the case of the symmetrical l-shaped has: $b_{f}=b_{f i}=b_{f s}$ and $t_{f}=t_{f i}=t_{f s}$.

\subsection{Design variables}

Design variables are parameters that describe the project and change their values throughout the optimization process. They can be of two distinct types: discrete (or integer, values within a certain fixed set) and continuous (real) variables. In this work, in the optimization process, the design variables are continuous being the parameters that

\section{Figure 1}

Deformation of a composite beam segment [1] 
define the steel beam I-shaped cross-section, the concrete slab rectangular cross-section and the area of the reinforcement bars of the concrete slab, as shown in Figure 2 and Eq. 10.

$\mathbf{x}^{T}=\left[\begin{array}{llllllllll}b & h & b_{f i} & t_{f i} & b_{f s} & t_{f s} & b_{w} & t_{w} & A_{s 1} & A_{s 2}\end{array}\right]$

As presented in section 3.6, the implemented algorithm initially defines values for the design variables considering them as continuous variables, thus defining dimensions for the steel profile, for the concrete slab and reinforcement not usual. To avoid this, a few steps after the definition of the optimized section were included in the algorithm considering the design variables as discrete, thus obtaining a section with usual dimensions.

\subsection{Design constraints}

Constraints are a set of requirements and conditions that must be satisfied in order for the project to be acceptable. It can also be said that they are equations or inequalities of the design variables that describe project situations that must be met.

Defining the materials properties according to technical specifications [21, 22], the ultimate and service limit load that the composite beam resists is obtained. These values are compared to the input data and define two constraints. In this work only compact section will be used; thus, the flange and web slenderness of the profile I will be limited so that flange and web local buckling does not occurs. Other restrictions that must be considered are lateral constraints, which are the lower and upper limits of concrete slab dimensions, steel profile I, reinforcement areas and step size. This last lateral constraint is defined so that the objective functions and constraints linear approximations used in the sequential linear programming method are valid.

\subsubsection{Ultimate limit state verfication}

The $f_{u}$ fator that multiplies the load (ultimate combination) supplied by the user to which the composite beam is imminent of ruin is determined. Eq. 11 provides the constraint related to the ultimate limit state of the composite beam.

$C_{1}(\mathbf{x})=f_{u}-1 \geq 0$

The value of $f_{u}$ equal to 1 means that the analyzed section resist, at the limit, a load equal to the load defined by the user. If it is larger than 1 , the section satisfies the ultimate limit state constraint.

\subsubsection{Service limit state verification}

The maximum vertical displacement is determined for each span of the beam considering in the analysis the load (service combination) provided by the user. For the different spans of the beam, the value of the maximum vertical displacement $(\delta)$ is determined for the span most susceptible to the verification of the service limit state. This value is compared with the limit vertical displacement $\left(\delta_{\lim }\right)$ specified by the user, as shown in Eq. 12.

$C_{2}(\mathbf{x})=1-\delta / \delta_{\text {lim }} \geq 0$

If $\delta=\delta_{\lim }$ implies that the analyzed section satisfies at the limit the maximum vertical displacement constraint. In case $\delta<\delta_{\lim }$ the ana- lyzed section satisfies the maximum vertical displacement constraint.

\subsubsection{Flange and web slenderness verification}

In this work, only a compact section is allowed, that is, according to NBR 8800 [22], the limit slenderness $\left(0,5 b_{f} / t_{f}\right)$ for AL type elements

is of $\lambda_{f}=0,38 \sqrt{E / f_{y}}$ and of $\lambda_{w}=3,76 \sqrt{E / f_{y}}$ for AA type

elements. Thus, we can define Eqs. 13 and 14 for the flange and web slenderness constraint, respectively.

$C_{3}(\mathbf{x})=\lambda_{f} t_{f i}-0,5 b_{f i} \geq 0$

$C_{4}(\mathbf{x})=\lambda_{w} t_{w}-b_{w} \geq 0$

\subsubsection{Lateral constraint}

The lateral constraints are lower and upper practical limits for the variables. For example, a variable referring to the diameter of the steel bars can not be less than the smaller commercial diameter of the bars and nor higher than the larger commercial diameter. This type of constraint is common to all constrained optimization problems.

The design variables vector $\mathbf{x}$ has already been defined. By defining the vectors $\overline{\mathbf{I}}$ and $\overline{\mathbf{u}}$ as the lower and upper limits of these variables, the set of constraints given by Eqs. 15 and 16 for the lateral constraints of the design variables are defined. In these equations, $i=1,2, \ldots, n$ with $n$ being the number of variables, that is, $\mathrm{n}=8$ for the symmetric case and $\mathrm{n}=10$ for the non-symmetric case.

$C_{i+4}(\mathbf{x})=x_{i}-\bar{l}_{i} \geq 0$

$C_{i+n+4}(\mathbf{x})=\overline{u_{i}}-x_{i} \geq 0$

In the search method of the optimum point presented in the item 3.4 , a starting point $x_{0}$ is defined and the next point that meets the design constraints and generates a reduction in the objective function is obtained from the iterative equation $x_{k+1}=x_{k+d}$, where $d$ is the step size. Thus, the non-linear problem analyzed becomes a sequence of linear problems with the variables given by vector d. In order to be valid the linear approximation used in the method

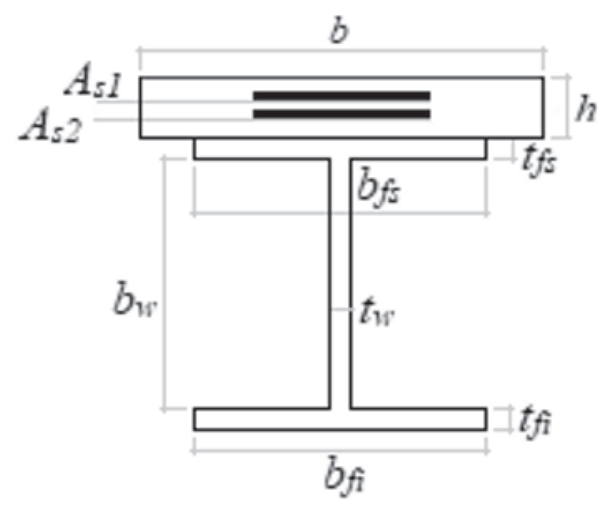

Figure 2

Design variables of the problem 
implemented in this work, lateral constraints must be imposed for the step size, that is, $|\mathrm{d}| \leq \Delta$. Therefore, we arrive at the set of constraints given by Eqs. 17 and 18, where i varies from 1 to $n$, with $n$ defined in the previous paragraph.

$C_{i+2 n+4}(\mathbf{d})=\Delta_{i}+d_{i} \geq 0$

$C_{i+3 n+4}(\mathbf{d})=\Delta_{i}-d_{i} \geq 0$

\subsection{Sequential linear programming}

The linear programming method is a mathematical solution applied to optimization problems where the objective function and all constraints represented by equations or inequalities of the design variables are linear with respect to these variables.

Eq. 19 is the mathematical form of presentation of the general optimization problem with equality and inequality constraints. In this equation, $f$ is the objective function to be minimized, $\mathbf{x}$ is the design variables vector, and $C$ and $D$ are functions of the design variables that define, in this order, the inequality and equality constraints of the analyzed problem.

$\min _{x} f(\mathbf{x})$ subject the $C_{i}(\mathbf{x}) \geq 0$ and $D_{j}(\mathbf{x})=0$

Eqs. 20 and 21 present the objective functions and constraints linearization using the Taylor series expansion truncated in the first order term, where $\nabla^{\top} f_{k}$ is a line vector with $n$ terms given by the first order partial derivatives of the objective function in relation to the design variables evaluated at point $x_{k}$. The term $\nabla^{\top} C_{i k}$ is defined in an analogous way, considering the functions that define the constraints.

$f\left(x_{k}+\mathbf{d}\right) \cong f\left(x_{k}\right)+\nabla^{T} f_{k} \mathbf{d}$

$C_{i}\left(x_{k}+\mathbf{d}\right) \cong C_{i}\left(x_{k}\right)+\nabla^{T} C_{\mathrm{ik}} \mathbf{d}$

Given a feasible starting point $x_{0}$, the problem presented in Eq. 19 can be analyzed iteratively using linear approximations of the objective functions and constraints and the iterative equation $x_{k+1}=x_{k+d}$. The step $\mathbf{d}$ is found by solving the linear optimization problem given in Eq. 22. In this work the Simplex method is applied to solve this linear optimization problem.

$\min _{d} \nabla^{T} f_{k} \mathbf{d}$ subject the $\nabla^{T} C_{i_{k}} \mathbf{d} \geq-C_{i}\left(\mathbf{x}_{k}\right)$

\subsection{Standard form for the analyzed problem}

To define the next step of the sequential linear programming method by means of the Simplex method, it is necessary to place the linear problem of Eq. 22 in the standard form of linear programming. By doing this, Eq. 23 for the linear optimization problem, which will define the step to be given in each iteration, is obtained. The formulation in this item is presented for non-symmetric l-shaped section ( $n=10$ and $m=44)$; in the case of symmetrical I-shaped section ( $n=8$ and $m=36$ ), the formulation is analogous.

$\min _{\mathbf{d} *}\left[\begin{array}{lll}\nabla^{T} f_{k} & -\nabla^{T} f_{k} & 0_{1 \times m}\end{array}\right] \mathbf{d}^{*}$ subject the

$\left[\left[\nabla^{T} C\right]_{m \times n}-\left[\nabla^{T} C\right]_{m \times n}-[\mathbf{I}]_{m \times m}\right] \mathbf{d} *=-[C]_{m \times 1}$

In Eq. 23, $\nabla f_{k}$ is as defined above, $d^{*}=\left[d^{+\top} d^{-\top} u^{\top}\right]^{\top}$, where $d^{+}$and $d^{-}$are two vectors with $n$ terms (number of design variables), $u$ is a vector with $\mathrm{m}$ terms (number of constraints), $\mathrm{I}_{\mathrm{mxm}}$ is an identity matrix of order $m$, and $0_{1 \times m}$ is a null line vector with $m$ terms. For more information on how to arrive at this standard form, see [23, 24]. Derivatives in relation to the ultimate and service loads are ob- tained using the finite difference method. Derivatives in relation to the objective function, the flange and web slenderness constraint, lateral constraint and step size control are obtained analytically by deriving their equations in relation to the $n$ design variables. Eq. 24 shows the derivatives of the objective function in relation to the $n$ design variables, whereas Eqs. 25 to 32 present the derivatives of the inequality constraints in relation to the $\mathrm{n}$ design variables.

$\nabla^{T} f_{k}=\left[\begin{array}{llllllllll}h C_{c} & b C_{c} & t_{f i} C_{a} & b_{f i} C_{a} & t_{f s} C_{a} & b_{f s} C_{a} & t_{w} C_{a} & b_{w} C_{a} & C_{b} & C_{b}\end{array}\right]$

$\nabla^{T} C_{1}=\left[\begin{array}{lll}\frac{\partial f_{u}}{\partial x_{1}} & \cdots & \frac{\partial f_{u}}{\partial x_{n}}\end{array}\right]$

$\nabla^{T} C_{2}=-\frac{1}{\delta_{\lim }\left[\begin{array}{lll}\frac{\partial \delta}{\partial x_{1}} & \cdots & \frac{\partial \delta}{\partial x_{1}}\end{array}\right]}$

$\nabla^{T} C_{3}=\left[\begin{array}{lllllll}0 & 0 & -\frac{1}{2} & \lambda_{f} & 0 & \ldots & 0\end{array}\right]$

$\nabla^{T} C_{4}=\left[\begin{array}{lllllll}0 & \ldots & 0 & -1 & \lambda_{w} & 0 & 0\end{array}\right]$

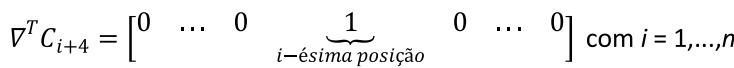

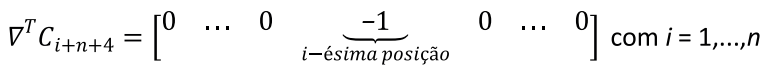

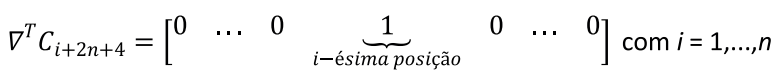

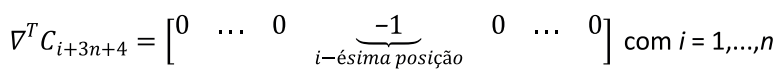

\subsection{Algorithm}

The following algorithm describes the iterative method to obtain an $\mathbf{x}$ vector that minimizes the objective function $f(\mathbf{x})$ and satisfies all design constraints discussed above.

Step 1 Reading of input data provided by the user: materials stress-strain curve of the composite beam, loading considering ultimate and service combination, support conditions, materials unit cost, limit parameters, beam discretization in bar and interfade finite element, analysis type (symmetrical or non-symmetrical l-shaped steel section), as well as the concrete slab, I-shaped steel section and reinforcement dimensions. These dimensions must be provided respecting the limit parameters. Other input data are the possible variations within the limit parameters for each design variable. This data is used by the program to define a discrete section from the optimized section obtained considering the design variables as continuous.

Step 2 Determine the starting point that meets all design constraints. This point is needed to start the iterative process of finding the optimal point using linear approximations to the constraints and objective function at each step. Through the structural analysis the algorithm verifies if the dimensions provided by the user meet the constraints. If not met, the algorithm increases dimensions by $10 \%$ until all constraints are satisfied.

Step 3 Use of sequential linear programming and the Simplex method to define the optimized section. Using the starting point of the previous step and the Simplex method, a new point is obtained by solving a linear optimization problem.

Step 4 Transforming the optimized section from the previous step into a section with discrete variables. The algorithm set the value of a design variable according to an available list and closer to the value obtained by the Simplex method. From there, this variable is eliminated and the problem is reanalyzed by setting new values for the other variables, 

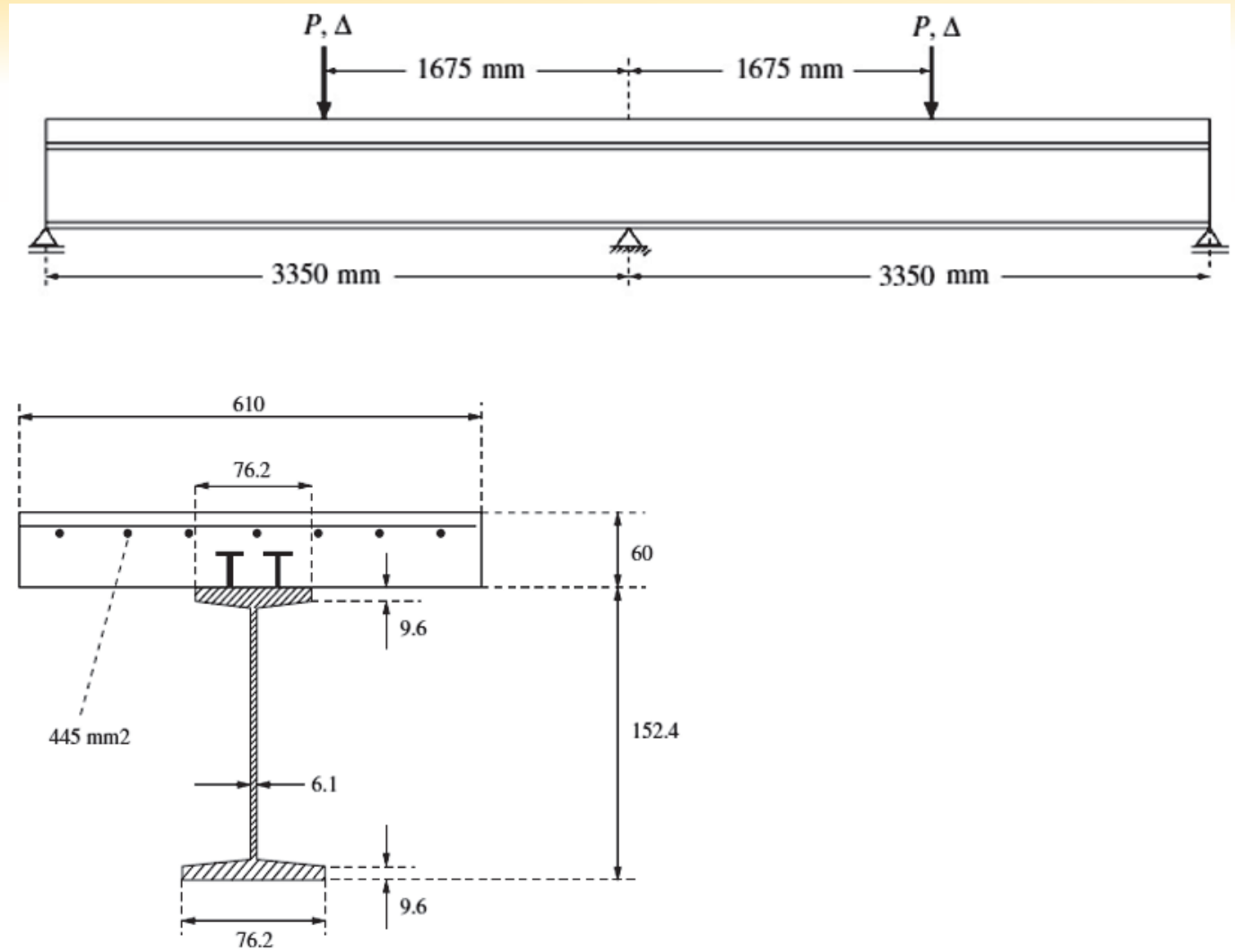

\section{Figure 3}

Composite beam with partial interation: continuous beam and cross-section [25]

and so on until all the design variables are defined according to the variation defined by the user.

\section{Applications}

In all the examples analyzed to verify the method proposed in this article, the nonlinear analyzes of the composite beams were done using the finite elements presented in item 2. Two of these examples are presented below.

\subsection{Example 1}

Salari and Spacone [25] analyzed the load capacity of a steel- concrete composite beam of two span with partial interaction, shown in Figure 3. In the numerical analysis, the authors used a bar finite element with ten degrees of freedom, capable of simulating the materials non-linearity. The constitutive relations of the materials used by Salari and Spacone [25] are shown in Figure 4.

The example of Figure 3 was also analyzed by Silva and Sousa [1]. The numerical results obtained by Salari and Spacone [25] and Silva and Sousa [1] are shown in Figure 5, where the curves that relate the applied load $\mathrm{P}$ to the vertical displacement $\Delta$ of the beam analyzed in this example are shown.

It is observed in Figure 5 that the maximum concentrated load supported by the composite beam analyzed is $132.3 \mathrm{kN}$, applied in the midspan. This value will be used as the solicitant load in a
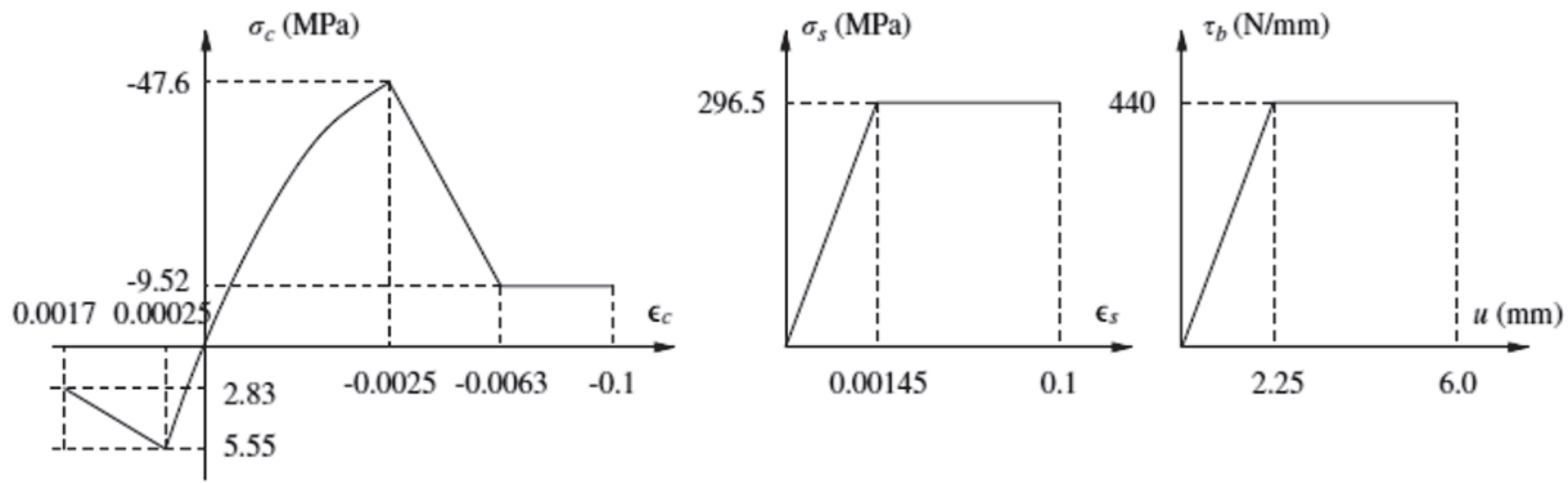

\section{Figure 4}

Constitutive laws used by Salari and Spacone [25], respectively: concrete, steel (profile and reinforcement) and interface connection 


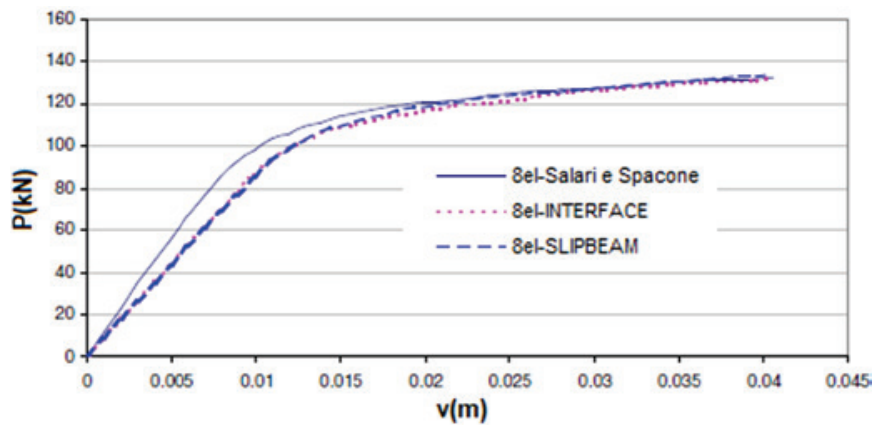

Figure 5

Load-displacement curve for a point in

the mipspan of the composite beam

continuous composite beam with the same configurations of the beam shown in Figure 3, for which the user will define any initial section and the optimization algorithm will provide an optimized section, validating its application.

In the numerical simulation of this work, 8 bar elements were used to simulate the concrete beam, 8 bar elements to simulate the steel beam and 8 interface elements to simulate the deformable connection.

\subsubsection{Optimizing l-shaped steel section}

It will be forced that the variables referring to the concrete slab section and reinforcement have final values equal to that of the section of Figure $3\left(A_{s 1}=445 \mathrm{~mm}^{2}, A_{\mathrm{s} 2}=0, b=610 \mathrm{~mm}\right.$ and $h=60 \mathrm{~mm}$ ). For this, a low cost for concrete and reinforcement and a high cost for steel will be defined in the input file, associated to upper limit values for the concrete section and the reinforcement dimensions equal to the values of the section dimension of Figure 3. Thus, in the search for the minimum cost, the algorithm will tend to reduce the Ishaped steel section more significantly until it reaches a point where it will begin to increase the concrete section and reinforcement dimensions to continue reducing the l-shaped steel section. The increase of the concrete section and reinforcement dimensions will end when the defined limits dimensions (lateral constraint) are reached; from there only the variables of the I-shaped steel section will be changed.

It is shown in Figure 6 the initial section provided by the user that must satisfy only the requirements of the limits dimensions also inserted in the input file. The section altered by the algorithm to meet load and slenderness requirements is also presented in Figure 6. This section is considered as the starting point of the optimization method in this example.

Table 1 shows the limits values defined for the design variables. As already mentioned, costs were provided by forcing concrete section ( $b$ and $h$ ) and reinforcement $\left(A_{s 1}\right.$ and $\left.A_{s 2}\right)$ variables to converge to their upper limit values.
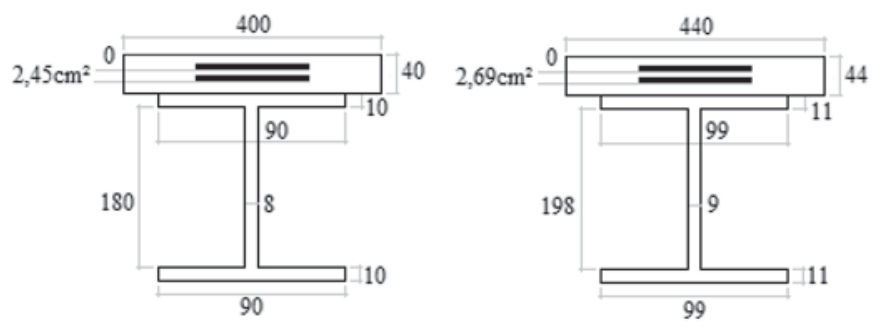

\section{Figure 6}

Section defined by the user and initial section defined by the algorithm (dimensions in $\mathrm{mm}$ )

In the assignment of the discrete values, the variation parameters provided by the user were $10 \mathrm{~mm}$ for the dimensions $b_{f}$ and $b_{w}$ bf and $1.0 \mathrm{~mm}$ for the dimensions $t_{f}$ and $t_{w}$. Thus, the widths will be discrete values with centimeter precision and the thicknesses will be discrete values with millimeter precision, between the lower and upper limits of each variable described in Table 1.

The implemented algorithm will provide a concrete section and reinforcements with dimensions equal to those of the Salari and Spacone section, and for the steel profile, the smallest I-shaped section that meets all design constraints will be provided. For the ultimate load constraint verification, a load of $132.3 \mathrm{kN}$ was considered concentrated in the beam midspan, and for the service load constraint verification the value of $70 \mathrm{kN}$ was considered for a load concentrated in the beam midspan, which is a load approximately equal to half the load obtained by a ultimate combination.

The response obtained in this example, considering symmetrical I-shaped section, is shown in Figure 7. As already expected, the

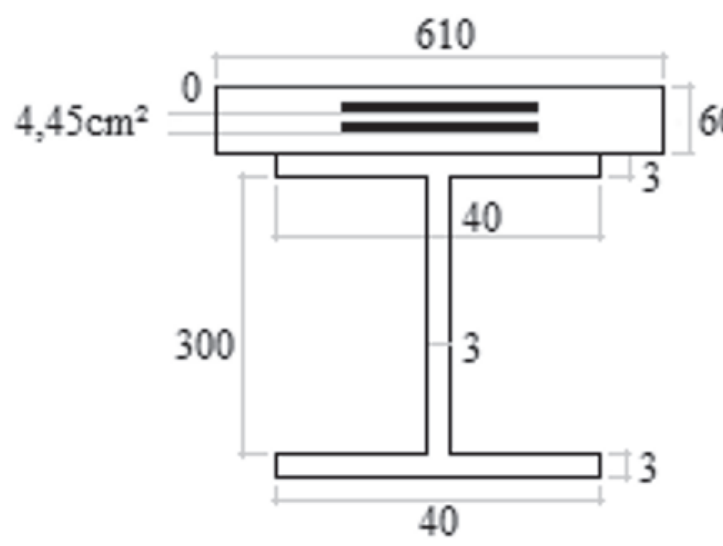

\section{Figure 7}

Optimized symmetric section obtained

by the algorithm (dimensions in $\mathrm{mm}$ )

\section{Table 1}

Limit parameter for design variables (dimensions in $\mathrm{mm}$ and area in $\mathrm{cm}^{2}$ )

\begin{tabular}{ccccccccc}
\hline Variables & $\mathbf{b}$ & $\mathbf{h}$ & $\mathbf{b}_{\boldsymbol{f}}$ & $\mathbf{t}_{\mathrm{f}}$ & $\mathbf{b}_{\mathbf{w}}$ & $\mathbf{t}_{\mathbf{w}}$ & $\mathbf{A}_{\mathrm{s} 1}$ & $\mathbf{A}_{\mathrm{s} 2}$ \\
\hline Lower limit & 200 & 10 & 40 & 2 & 80 & 2 & 0 & 0 \\
Upper limit & 610 & 60 & 1000 & 100 & 2000 & 100 & 4.4 & 0 \\
\hline
\end{tabular}




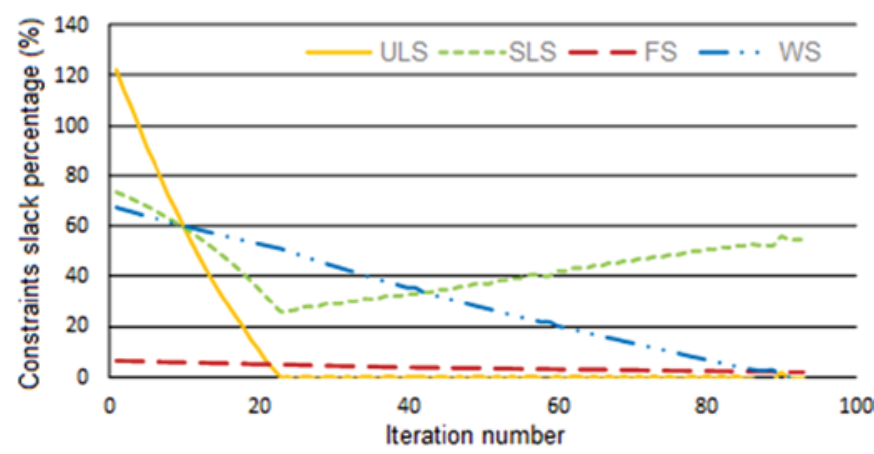

Figure 8

Variation of the constraints in the optimization process (symmetric profile)

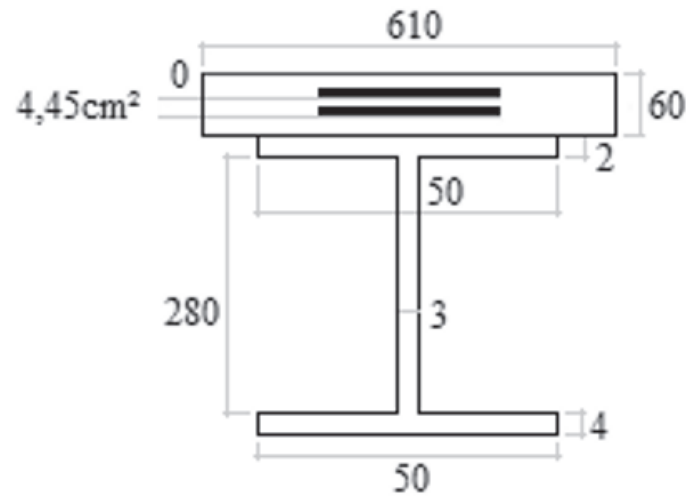

\section{Figure 9}

Optimized non-symmetric section obtained by the algorithm (dimensions in $\mathrm{mm}$ )

reinforced concrete section is equal to the section of Salari and Spacone. The symmetrical l-shaped section presents a total area of $1,140 \mathrm{~mm}^{2}$, while the Salari and Spacone section presents an area of $2,390 \mathrm{~mm}^{2}$. It can be noticed that the optimization algorithm started from an initial section, given in Figure 6 , with area of $3,960 \mathrm{~mm}^{2}$ and converged to an section $71.2 \%$ smaller than the starting section and $52.3 \%$ smaller in relation to the Salari and Spacone section.

Figure 8 shows the variations of the ultimate and service limit state constraints, flange and web slenderness constraints, in relation to the number of iterations. In this figure, ULS refers to the constraint given by the ultimate load, SLS refers to the constraint given by the service load, FS and AS make references to the flange and web slenderness constraint, respectively. It can be seen that the starting section has a slack of $122 \%, 73 \%, 6 \%$, and $67 \%$ in relation to these restrictions, respectively. Note that the ultimate limit state verification is decisive when compared to the service limit state, since the optimized section has a gap of $54 \%$ in relation to the service limit state, and no slack in relation to the ultimate limit state. It is also noticeable that the web slenderness presents enough slack at the beginning of the iterations, ending without slack, and the flange slenderness, presents a small slack throughout the iterative process.

The same analyzes made for the symmetrical I-shaped section were performed for the non-symmetric case and are presented below. Figure 9 shows the response to the non-symmetric optimized section and it can be seen that the reinforced concrete section is equal to the Salari and Spacone section, as it should be, and that the non-symmetrical I-shaped section has a total area of 1,140 $\mathrm{mm}^{2}$. In the same way as for the symmetric section, the optimization algorithm started from the section given by Figure 6 and converged to a section $71.2 \%$ smaller than the starting section and $52.3 \%$ smaller than the Salari and Spacone section.

The figure of the variations of the constraints for the non-symmetric case is practically the same for the symmetric section and therefore is not presented.

\subsubsection{Optimizing concrete slab}

In this example, the same characteristics of the example analyzed in the previous sub-item will be considered, but any initial section will be defined and the optimization algorithm will provide a symmetrical I-shaped section equal to the authors section and will optimize the concrete slab section.

The initial section provided by the user is shown in Figure 10. As in the previous example, this section should satisfy only the requirements of the limits dimensions. In this example, the section provided by the user meets all design constraints and is then taken as the starting section for the optimization algorithm.

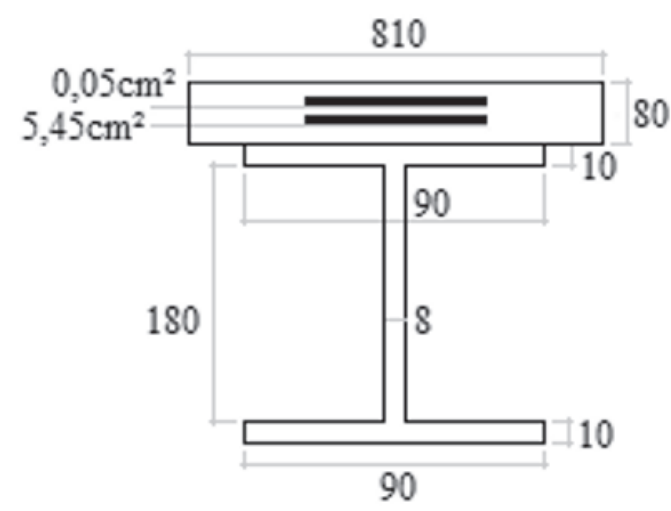

Figure 10

Section defined by the user and initial section defined by the algorithm (dimensions in $\mathrm{mm}$ )

\section{Table 2}

Limit parameter for design variables (dimensions in $\mathrm{mm}$ and area in $\mathrm{cm}^{2}$ )

\begin{tabular}{ccccccccc}
\hline Variables & $\mathbf{b}$ & $\mathbf{h}$ & $\mathbf{b}_{\mathrm{f}}$ & $\mathbf{t}_{\mathrm{f}}$ & $\mathbf{b}_{\mathbf{w}}$ & $\mathbf{t}_{\mathbf{w}}$ & $\mathbf{A}_{\mathrm{s} 1}$ & $\mathbf{A}_{\mathrm{s} 2}$ \\
\hline Lower limit & 100 & 40 & 76.2 & 9.6 & 133.2 & 6.1 & 4.4 & 0 \\
Upper limit & 2000 & 250 & 1000 & 100 & 2000 & 100 & 5.4 & 0.01 \\
\hline
\end{tabular}




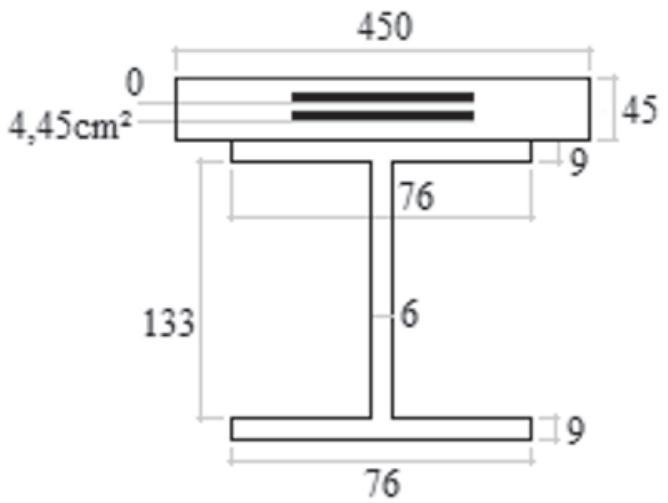

Figure 11

Optimized symmetric section obtained

by the algorithm (dimensions in $\mathrm{mm}$ )

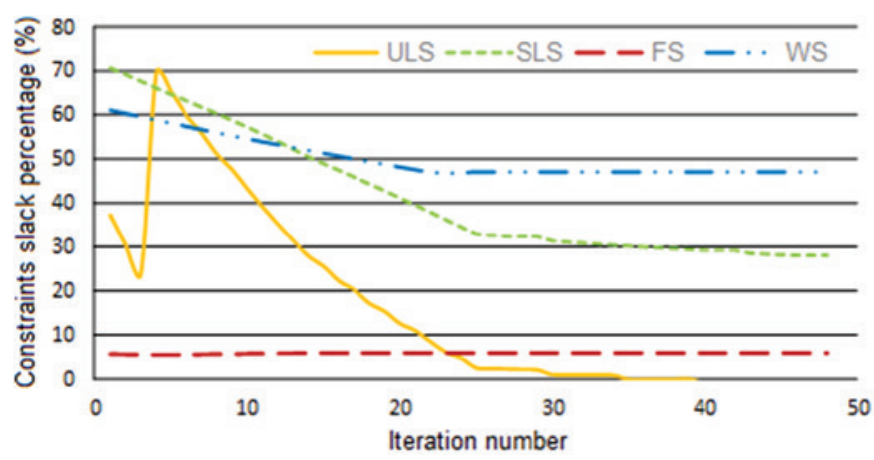

Figure 12

Variation of the constraints in the optimization process (concrete slab)

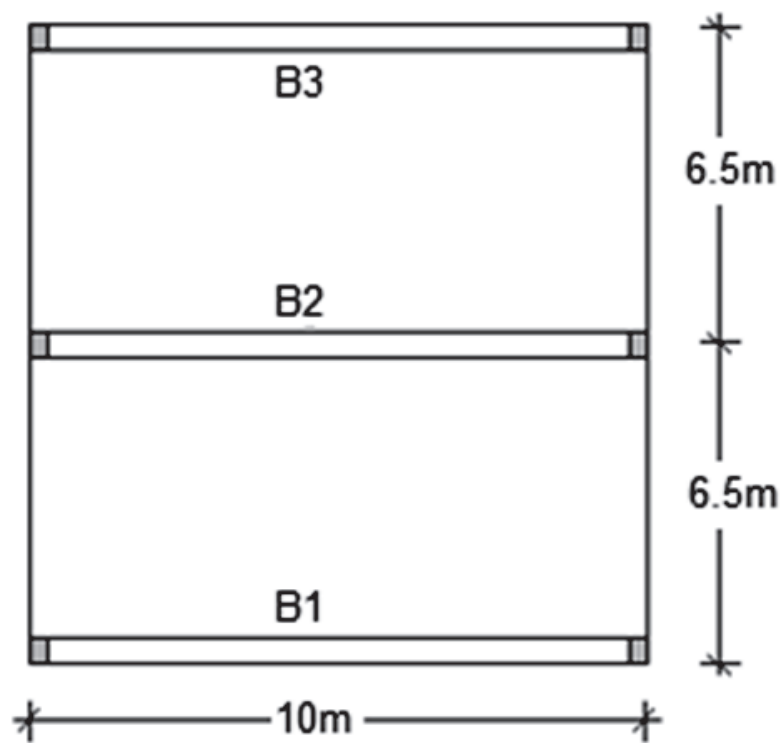

Figure 13

Composite floor formed by concrete slab and simply supported steel beams
The limits parameters for the design variables provided by the user are shown in the Table 2. As mentioned, these values will serve as limits for the design variables (lateral constraints), noting that the costs were defined so that the variables related to the steel profile $\left(b_{f}, t_{f}, b_{w}\right.$ e $\left.t_{w}\right)$ and reinforcement $\left(A_{s 1}\right.$ e $\left.A_{s 2}\right)$ converge to their lower limit values.

In the assignment of the discrete values, the variation parameters provided by the user were $10 \mathrm{~mm}$ for dimension $b, 5 \mathrm{~mm}$ for $h$ and $0.1 \mathrm{~mm}$ for dimensions $b_{f}, t_{f}, b_{w}$ and $t_{w}$. Thus, the concrete slab height will be a discrete value with an accuracy of $5 \mathrm{~mm}$ between the lower and upper limits parameters given in Table 2, that is, a discrete value in the list: $40,45,50, \ldots, 240,245,250 \mathrm{~mm}$.

In Figure 11 the response obtained for this example is shown. In this figure it is observed that the reinforcement and I-shaped steel section are equal to Salari and Spacone section, as predicted, and the concrete section presents total area of $20,250 \mathrm{~mm}^{2}$, whereas the Salari and Spacone concrete section has an area of 36,600 $\mathrm{mm}^{2}$. Thus, it is noted that the optimization algorithm started from any section given in Figure 6, with an area of $64,800 \mathrm{~mm}^{2}$, and converged to a section $68.8 \%$ smaller than that the starting section and $44.6 \%$ smaller than the Salari and Spacone section.

It can be seen in Figure 12 that the starting section has a slack of $37 \%, 71 \%, 5 \%$, and $61 \%$, respectively, in relation to the ultimate and service limit state constraints, and the flange and web slenderness constraint. It is verified in the same figure that, for the vertical displacement limit and the service load established equal to the previous sub-item, the ultimate limit state verification is determinant when compared to the service limit state verification, since the optimized section has a slack of $28 \%$ for the service limit state.

\subsection{Example 2}

The composite floor of Figure 13 is formed by a concrete slab $\left(f_{c k}\right.$ $=20 \mathrm{MPa})$ supported on three AR 350 steel beams $\left(f_{y}=350 \mathrm{MPa}\right)$ simply supported at the ends. For the definition of the ultimate and service load on the beams an variable action of $2 \mathrm{kN} / \mathrm{m}^{2}$ (office floor) is considered, as well as a permanent action of self-weight of concrete slab of $3.8 \mathrm{kN} / \mathrm{m}^{2}$ and of the steel beam of $0.8 \mathrm{kN} / \mathrm{m}$ (selfweight of the l-shaped profile per linear meter). It is considered that the central beam receives half of the loading of the floor and the other half is equally divided between the ends beams.

In this example the composite beam dimensions formed by the concrete slab and the central beam (B2 beam in Figure 13) will be determined in order to minimize a cost function related to the concrete, steel profile and reinforcement cost. The beam is given by a symmetrical I-shaped section, the reinforcement by $10 \mathrm{~mm}$ CA50 steel bars and the rectangular concrete slab with thickness to be determined and width given by the concept of effective width [22]. According to the data provided in the previous paragraphs, in Figure 13 , and in the conditions of combinations of actions for verification of the ultimate and service limit states [22], we arrive at the design value for ultimate and service loads given by $55.16 \mathrm{kN} / \mathrm{m}$ and $30.7 \mathrm{kN} / \mathrm{m}$, respectively. According to this same design code [22] the effective width $(b)$ is of $2.5 \mathrm{~m}$.

The materials non-linearity is represented by their stress-strain curves and the shear force-slip curve of the deformable connection. 
In this example the stress-strain curves shown in Figure 14 are used $[21,22]$. For the shear force-slip curve of the deformable connection it is considered the use of stud bolt shear connectors of $19.1 \mathrm{~mm}$ diameter uniformly spaced every $20 \mathrm{~cm}$. The connector steel has $f_{y}$ $=345 \mathrm{MPa}$ and $f_{u}=415 \mathrm{MPa}$. For more details on how to obtain this curve consult to the references [26, 27].

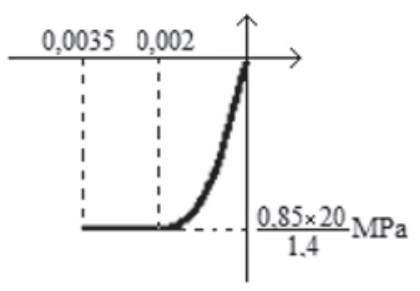

a

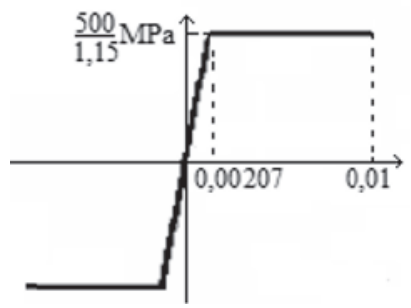

c

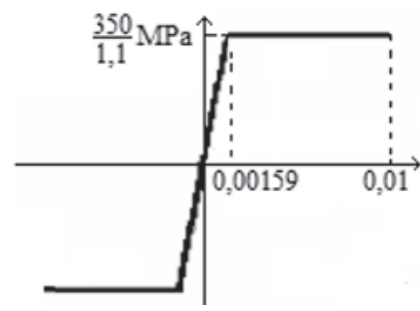

b

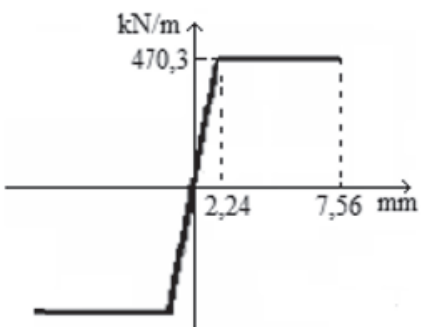

d

\section{Figure 14}

Constitutive laws used in this example: (a) concrete, (b) steel profile, (c) reinforcement and (d) interface connection

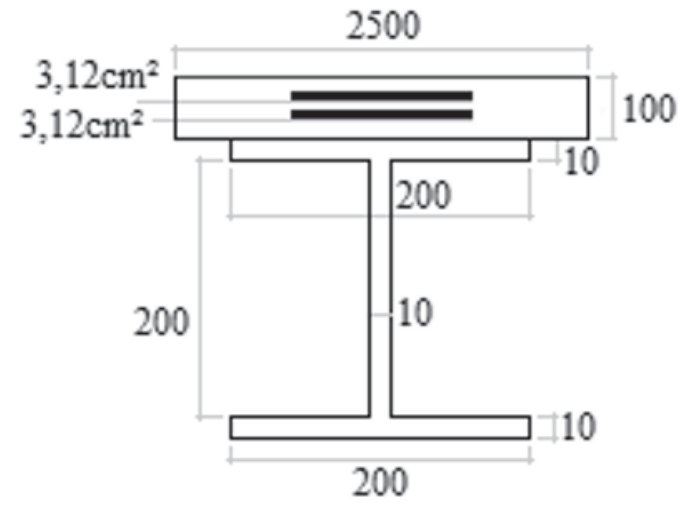

Figure 15

Section defined by the user (dimensions in $\mathrm{mm}$ )
For numerical analysis, a discretization of the B2 composite beam of Figure 13 was made as follows: 4 beam elements to simulate the concrete beam, 4 beam elements to simulate the steel beam, and 4 interface elements to connect the beam elements and simulate the deformable connection.

In the definition of the objective function it is necessary that the user provides the concrete, steel profile and reinforcement cost. In this example, the values of $\mathrm{R} \$ 350 / \mathrm{m}^{3}, \mathrm{R} \$ 31,000 \mathrm{R} / \mathrm{m}^{3}$, and $\mathrm{R} \$ 50,000 / \mathrm{m}^{3}$ for concrete, steel profile and reinforcement materials, respectively, were adopted.

The initial section provided by the user for this example is shown in Figure 15. The initial section must meet only the requirements of the limit dimensions. As in the other examples, if the flange and web slenderness constraints and the ultimate and service limit states constraints are not satisfied, the section is altered by the algorithm and has its dimensions enlarged in an iterative process until all constraints are satisfied. This section is taken as the starting point for the optimization procedure. In this example, the initial section of Figure 15 did not meet the constraints and the section that was altered by the algorithm is shown in Figure 16.

The values provided by the user for the design variables are shown in Table 3. It is observed from this table that the variable $b$ has a small variability and whatever its value within that variability the final dimension assigned will be the value of $2.5 \mathrm{~m}$. This is because in the process of transformation of this continuous variable into a discrete value a variation of $50 \mathrm{~mm}$ is used. For the other variables, the variation parameters provided by the user are $5 \mathrm{~mm}$ for $h, 10 \mathrm{~mm}$ for $b_{f}$ and $b_{w}$, and $1.0 \mathrm{~mm}$ for the dimensions of $t_{f}$ and $t_{w}$. In this example, the algorithm will define a section with concrete slab width $(b)$ equal to $2.5 \mathrm{~m}$ and the other dimensions will be defined within the specified limits in order to minimize the objective function related to materials cost. The response obtained from this

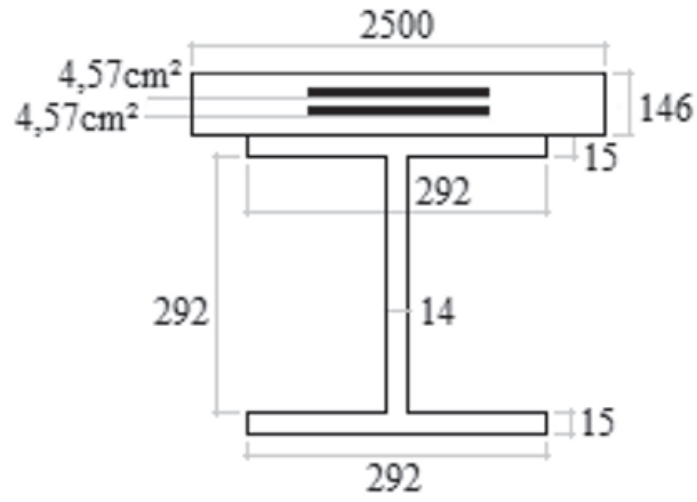

Figure 16

Starting section defined by the algorithm (dimensions in $\mathrm{mm}$ )

\section{Table 3}

Limit parameter for design variables (dimensions in $\mathrm{mm}$ and area in $\mathrm{cm}^{2}$ )

\begin{tabular}{ccccccccc}
\hline Variables & $\mathbf{b}$ & $\mathbf{h}$ & $\mathbf{b}_{\mathbf{f}}$ & $\mathbf{t}_{\mathbf{f}}$ & $\mathbf{b}_{\mathbf{w}}$ & $\mathbf{t}_{\mathbf{w}}$ & $\mathbf{A}_{\mathbf{s 1}}$ & $\mathbf{A}_{\mathbf{s} 2}$ \\
\hline Lower limit & 2460 & 70 & 50 & 20 & 200 & 2 & 2.49 & 2.49 \\
Upper limit & 2500 & 250 & 1000 & 100 & 2000 & 100 & 20 & 20 \\
\hline
\end{tabular}




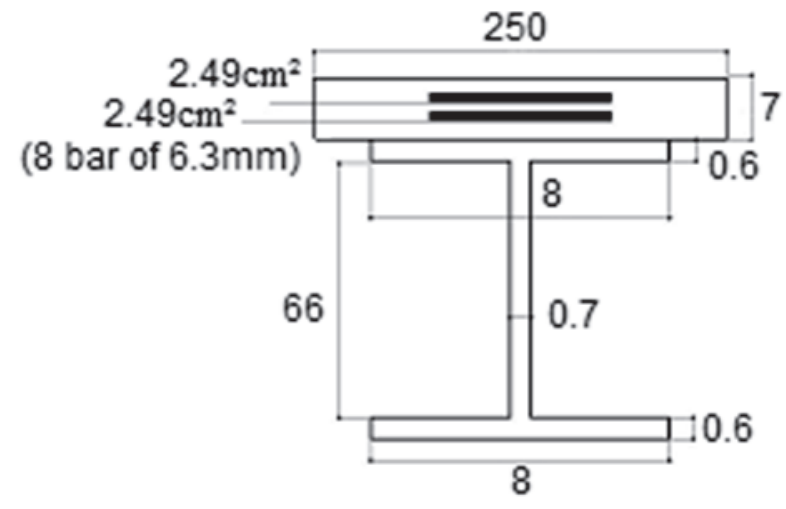

Figure 17

Optimum symmetric section obtained

by the algorithm (dimensions in $\mathrm{cm}$ )

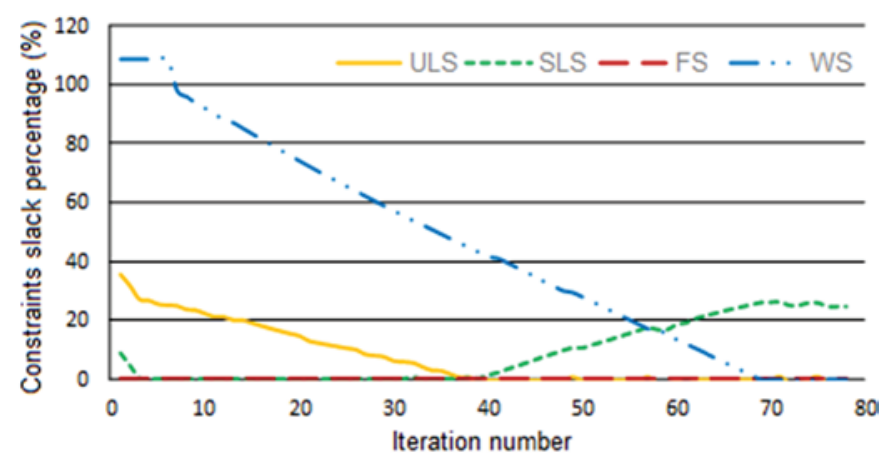

\section{Figure 18}

Variation of the constraints in the optimization process (symmetrical profile)

example, considering a symmetrical l-shaped section, is shown in Figure 17. It can be seen from this figure that the optimized section presents the concrete slab width of $2.5 \mathrm{~m}$ as desired. For the concrete slab thickness $(h)$ and for the reinforcement $\left(A_{s 1}\right.$ and $\left.A_{s 2}\right)$, its minimum limit values were defined.

Figure 18 below shows the variations of the constraints in relation to the number of iterations. It is observed from this figure that the starting section presents a slack of $35 \%, 9 \%, 0 \%$, and $109 \%$, respectively, in relation to the ultimate and service limit state constraints, and the flange and web slenderness constraint. In this figure it is observed that the ultimate limit state is determinant in design. In the iteration 38 the slacks in relation to the two limit states were zero, however, the slack of $45 \%$ in relation to the web slenderness allowed the continuation of the method providing a section with limit value for the web slenderness and $25 \%$ of slack for the service limit state. The flange slenderness presents without slack throughout the iterative process.

In Figure 19 is presented the variation of the composite beam materials cost during the iterative process of the method presented in this work. The starting section presents a cost of $R \$ 586.61 / \mathrm{m}$ while the optimized section presents a cost of $R \$ 265.01 / \mathrm{m}$, a reduction of $54.8 \%$.

The same analyzes made considering a symmetrical I-shaped section were performed considering non-symmetrical I-shaped section. The section defined by the user and the starting section of the algorithm are the same as the symmetric case. Table 4 presents the limit parameter defined by the user for the design variables.

The optimum non-symmetric section obtained by the algorithm is shown in Figure 20. In this figure it is observed that the upper flange is smaller than the lower flange, which is justified because the composite beam is subjected only to positive moments.

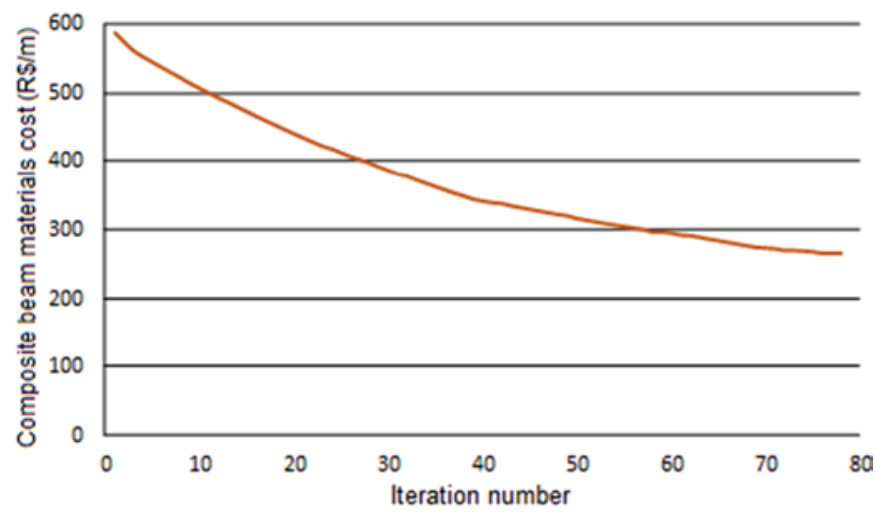

Figure 19

Variation of cost per linear meter of composite beam (symmetrical profile)

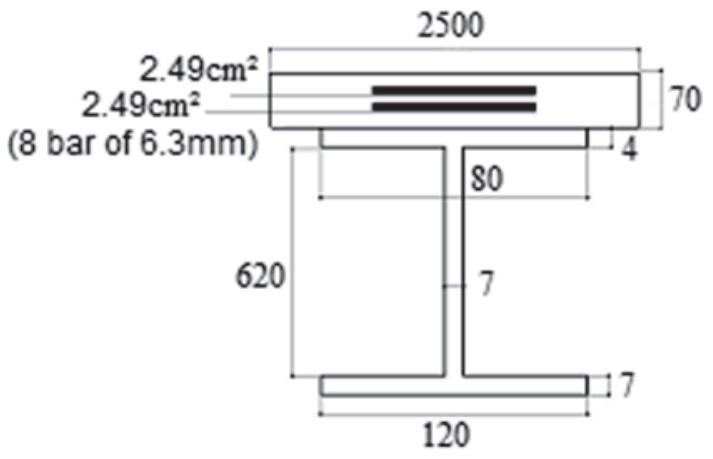

Figure 20

Optimum non-symmetric section obtained by the algorithm (dimensions in $\mathrm{mm}$ )

\section{Table 4}

Limit parameter for design variables (dimensions in $\mathrm{mm}$ and area in $\mathrm{cm}^{2}$ )

\begin{tabular}{ccccccccc}
\hline Variables & $\mathbf{b}$ & $\mathbf{h}$ & $\mathbf{b}_{\boldsymbol{f}}$ & $\mathbf{t}_{\boldsymbol{f}}$ & $\mathbf{b}_{\mathbf{w}}$ & $\mathbf{t}_{\mathbf{w}}$ & $\mathbf{A}_{\mathrm{s1}}$ & $\mathbf{A}_{\mathrm{s} 2}$ \\
\hline Lower limit & 2460 & 70 & 50 & 20 & 200 & 2 & 2.49 & 2.49 \\
Upper limit & 2500 & 250 & 1000 & 100 & 2000 & 100 & 20 & 20 \\
\hline
\end{tabular}


The curves of the variation of the constraints and of the composite beam materials cost with the iterations is very similar to the symmetrical case. The starting section presents a cost of $R \$ 586.61$ while the optimized section presents a cost of $R \$ 251.12$, a reduction of $57.2 \%$. Compared with the symmetric case, there is a reduction of $5.2 \%$.

\section{Conclusion}

This article consists of the implementation of an algorithm to define the dimensions of the symmetrical or non-symmetrical I-shaped steel profile, the dimensions of the rectangular concrete slab and the amount of reinforcement, so that the steel-concrete composite beam with partial interaction subject to simple bending meets the requirements of design code, minimizing an objective function defined from the amount and cost of the materials.

The sequential linear programming method was used to solve the nonlinear problem of the calculation of the efforts in the composite section for different values of the design variables. At each step of the sequential process the Simplex method was used to define the next step in order to guarantee an advance towards the minimum point. With the efficiency of the formulations of the finite elements used, the method proposed for the search of the optimized section had its efficiency duly proven from the results observed in the presented examples.

\section{Acknowledbments}

The authors would like to thank the Federal University of Ouro Preto (UFOP) /PROPEC, CNPq and FAPEMIG for collaboration.

\section{References}

[1] SILVA, A. R., SOUSA Jr., J. B. M. Nonlinear analysis of partially connected composite beams using interface elements. Finite Elements in Analysis and Design, v. 43, p. 954-964, 2007.

[2] R. XU, Y.F. Wu, Two-dimensional analytical solutions of simply supported composite beams with interlayer slips, Int. J. Solids Struct. 44 (2007) 165-175.

[3] A. DALL'ASTA, A. ZONA, Three-field mixed formulation for the non-linear analysis of composite beams with deformable shear connection, Finite Elem. Anal. Des. 40 (2004) 425448.

[4] G. RANZI, F. GARA, G. LEONI, M.A. BRADFORD, Analysis of composite beams with partial shear interaction using available modelling techniques: a comparative study, Comput. Struct. 84 (2006) 930-941.

[5] G. RANZI, A. ZONA, A steel-concrete composite beam model with partial interaction including the shear deformability of the steel component, Eng. Struct. 29 (2007) 3026-3041.

[6] S. SCHNABL, M. SAJE, G. TURK, I. PLANINC, Locking-free two-layer Timoshenko beam element with interlayer slip, Finite Elem. Anal. Des. 43 (2007) 705-714.

[7] A. DALL'ASTA, A. ZONA, Slip locking in finite elements for composite beams with deformable shear connection, Finite Elem. Anal. Des. 40 (2004) 1907-1930.

[8] F. GARA, G. RANZI, G. LEONI, Displacement-based formulations for composite beams with longitudinal slip and vertical uplift, Int. J. Numer. Methods Eng. 65 (8) (2006) 1197-1220.

[9] SOUSA JR, JOÃO BATISTA M. ; SILVA, A. R. . Analytical and numerical analysis of multilayered beams with interlayer slip. Engineering Structures, v. 32, p. 1671-1680, 2010.

[10] SILVA, A. R.; SOUSA JR., JOÃO BATISTA M. . A family of interface elements for the analysis of composite beams with interlayer slip. Finite Elements in Analysis and Design, v. 45, p. 305-314, 2009.

[11] SOUSA JR., JOÃO BATISTA M. ; OLIVEIRA, CLAUDIO E.M. ; SILVA, A. R. . Displacement-based nonlinear finite element analysis of composite beam columns with partial interaction. Journal of Constructional Steel Research, v. 66, p. 772-779, 2010.

[12] KRAVANJA, S.; SILIH, S. The MINLP optimisation of composite I-beams. Transactions on the Built Environment, v. 52, p. 401-407, 2001.

[13] KRAVANJA, S.; SILIH, S. Optimization based comparison between composite I beams and composite trusses. Journal of Constructional Steel Research, v. 59, p. 609-625, 2003.

[14] KLANŠEK, U.; KRAVANJA, S. Comparison between three different composite systems. High Performance Structures and Materials II, v. 52, p. 87-97, 2004.

[15] KLANŠEK, U.; KRAVANJA, S. Cost estimation, optimization and competitiveness of different composite floor systems Part 1: Self-manufacturing cost estimation of composite and steel structures. Journal of Constructional Steel Research, v. 62 , p. 434-448, 2006a.

[16] KLANŠEK, U.; KRAVANJA, S. Cost estimation, optimization and competitiveness of different composite floor systems - Part 2: Optimization based competitiveness between the composite I beams, channel-section and hollow-section trusses. Journal of Constructional Steel Research, v. 52, p. 449-462, 2006b.

[17] KLANŠEK, U.; KRAVANJA, S. Cost optimization of composite I beam floor system. American Journal of Applied Sciences, v. 5, p. 7-17, 2007.

[18] SENOUCI, A. B.; AL-ANSARI, M. S. Cost optimization of composite beams using genetic algorithms. Advances in Engineering Software, v. 40, p. 1112-1118, 2009.

[19] ABADI, A. S. M.; KAVEH, A. Cost optimization of a composite floor system using an improved harmony search algorithm. Journal of Constructional Steel Research, v. 66, p. 664-669, 2010.

[20] SILVA, A. R., SOUSA Jr., J. B. M.; NEVES, F. A. Optimization of steel-concrete composite beams with partial interaction by sequential linear programming. XXXII CILAMCE. Ouro Preto, 2011.

[21] ASSOCIAÇÃO BRASILEIRA DE NORMAS TÉCNICAS (ABNT). NBR 6118: projeto de estruturas de concreto - procedimento. Rio de Janeiro, 2014. (in portuguese)

[22] ASSOCIAÇÃO BRASILEIRA DE NORMAS TÉCNICAS (ABNT). NBR 8800: projeto de estruturas de aço e de estruturas mistas de aço e concreto de edifícios. Rio de Janeiro, 2008. (in portuguese)

[23] VANDERPLAATS, G., 1984. Numerical optimization technique for tnginnering design - with applications. McGraw-Hill Book Company, New York, 1984. 
[24] HAFTKA, R.; KAMAT, M. Elements of structural optimization. Martinus Nijhoff Publishers, Boston, 1985.

[25] SALARI, M. K.; SPACONE, E. Finite element formulation of one-dimensional elements with bond-slip. Engineering Strucutures, v. 23, p. 815-826.

[26] OEHLERS, D. J.; BRADFORD, M. A. Composite steel and concrete structural members: fundamental behaviour. Pergamon Press, Oxford, 1995.

[27] OLLGAARD, J. G.; SLUTTER, R. G.; FISHER, J. W. Shear strength of stud connectors in lightweight and normal-weight concrete. AISC Eng, v. J, p. 55-64, 1971. 